\title{
Proteomic analysis of extremely severe hand, foot and mouth disease infected by enterovirus 71
}

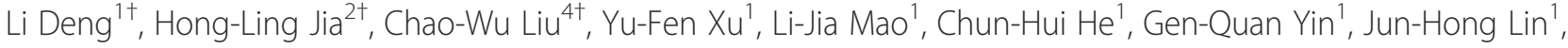
Jian-Ping Tao ${ }^{1}$ and Li Zhu ${ }^{3^{*}}$

\begin{abstract}
Background: To clarify the molecular mechanisms that participate in the severe hand, foot and mouth disease (HFMD) infected by Enterovirus 71 and to detect any related protein biomarkers, we performed proteomic analysis of protein extracts from 5 extremely severe HFMD children and 5 healthy children.

Methods: The protein profiles of them were compared using two-dimensional electrophoresis. Differentially expressed proteins were identified using mass spectrometry. Functional classifications of these proteins were based on the PANTHER. The interaction network of the differentially expressed protein was generated with Pathway Studio.
\end{abstract}

Results: A total of 38 differentially expressed proteins were identified. Functional classifications of these proteins indicated a series of altered cellular processes as a consequence of the severe HFMD. These results provided not only new insights into the pathogenesis of severe HFMD, but also implications of potential therapeutic designs.

Conclusions: Our results suggested the possible pathways that could be the potential targets for novel therapy: viral protection, complement system and peroxide elimination.

Keywords: Extremely severe HFMD, MALDI-TOF/TOF MS, Proteomic analysis

\section{Background}

Human enterovirus 71 (EV71) and coxsackievirus A16 (CA16) are two predominant pathogens causing HFMD. EV71 is more associated with major outbreaks and causes complications of greater severity, severe neurologic symptoms, and higher rates of mortality than other enteroviruses [1-4]. Outbreaks of EV71 have been reported since 1969 [1]. Especially since the late 1990s, a significant increase in EV71 epidemics is observed, creating a serious threat to public health throughout the Asia-Pacific region [5-7]. For example, in 2007, more than 80,000 HFMD cases were reported with dozens of deaths in mainland China $[8,9]$.

The complications of severe HFMD include pneumonia, myocarditis, encephalitis, brain-stem encephalitis and acute flaccid paralysis. High mortality and severe sequelae can be

\footnotetext{
*Correspondence: lizhu_89@126.com

${ }^{\dagger}$ Equal contributors

${ }^{3}$ School of Public Health and Tropical Medicine, Southern Medical University, Guangzhou 510515, Guangdong, China

Full list of author information is available at the end of the article
}

anticipated when the disease is complicated by neurogenic pulmonary edema, rapid disease progression $[10,11]$.

Only a small fraction of the mild cases further develop to the severe and fatal cases. However, these cases often progress rapidly and cause failure and deaths before effective treatment take place. As the rapid progression of symptoms in fatal cases, rapid diagnosis is essential for severely EV71-infected patients to provide timely treatment [12]. EV71 virus can be detected by testing viral antigens, viral genomic RNA and antiviral antibodies in HFMD patients [13-15], however, no quick method has been established to distinguish mild HFMD from severe HFMD during the rapid progression of symptoms in fatal cases of EV71 infection.

Two-dimensional gel electrophoresis (2-DE) and MALDITOF/TOF mass spectrometry have been extensively applied to identify differentially expressed proteins between different stages of disease, as well as those in healthy individuals, in a wide variety of biological systems [16]. This strategy is able to detect potential biomarkers for disease diagnosis, progression and therapy while does not require 
much knowledge background of the disease. In this study, we used comparative proteomics to systemically study the protein profile changes in serum of extremely severe HFMD. The proteome map presented here may serve as an important basis for future studies.

\section{Methods}

Preparation of serum samples

Blood samples from 5 HFMD children (five extremely severe) according to the foot and mouth disease prevention control guide' (2008 Edition) issued by the Ministry of Health, China (http://www.moh.gov.cn/publicfiles/business/ htmlfiles/mohbgt/s9511/200805/34775.htm), were randomly selected to be analyzed with 2-D Gel Electrophoresis and MALDI-TOF-MS and clinical symptoms and laboratory test (EV71 nucleic acid detection kit) confirmed that the EV71 infections caused all these HFMD cases. In addition to meeting the above symptoms, these children all had encephalitis, pulmonary hemorrhage, and mechanical ventilation and other clinical symptoms. They were proven to have no other disease after a systematic check in the hospital. Another five blood samples from healthy children were collected as controls. The protocols applied in this study were approved by the Ethical Committee of Guangzhou Women and Children's medical center. The parents of all participants of this study provided written informed consent. A pooled sample consists of equal amounts of each of 5 experimental samples. Blood sample was separated by centrifugation at $1000 \mathrm{~g}$ for $20 \mathrm{~min}$. Aliquots of serum were collected and stored at $-80^{\circ} \mathrm{C}$ until ready for use. Serum samples were processed using the ProteoExtract ${ }^{\circ}$ Albumin/IgG Removal Kit (Merck, New jersey, USA) that selectively removes IgG and albumin from the serum sample. Serum samples were handled according to the manufacture's instructions. To purify the protein extraction and determine the final protein concentration, the 2-D Clean-up Kit (GE healthcare, UK) and Bradford protein assay kit (Bio-Rad, USA) were used sequentially, following the manufacturer's instructions.

\section{Two-dimensional (2D) gel electrophoresis}

Total proteins were mixed up to $250 \mu \mathrm{L}$ of rehydration solution (8 M urea, $20 \mathrm{mM}$ DTT, 2\% CHAPS, and 0.5\% IPG buffer). For each sample $300 \mu \mathrm{g}$ of total protein were used for the experiment. 2-DE gel was performed with Amersham Biosciences IPGphor IEF System and Hoefer SE 600 (GE Healthcare) electrophoresis units using a 13-cm immobilized $\mathrm{pH} 3-10$ nonlinear gradient IPG strips according to the protocol suggested by the manufacturer. The rehydration step was performed for $10 \mathrm{~h}$ at low voltage of $30 \mathrm{~V}$. IEF was run by following a step-wise voltage increase protocol: 500 and $1000 \mathrm{~V}$ for $1 \mathrm{~h}$ each and 5000-8000 V for about $10 \mathrm{~h}$ with a total of $64 \mathrm{kVh}$. After IEF, the strips were subjected to two-step equilibration in equilibration buffers (6M urea, $2 \%$ SDS, $30 \%$ glycerol and $50 \mathrm{mM}$ Tris- $\mathrm{HCl} \mathrm{pH} 6.8$ ) with $1 \%$ DTT w/v for the first step, and $2.5 \%$ iodoacetamide $(\mathrm{w} / \mathrm{v})$ for the second step. The equilibrated gel strip was placed on top of a $12.5 \%$ SDS-PAGE gel, sealed with $0.5 \%$ agarose containing a little bromophenol blue. SDSPAGE was carried out at a constant current of $15 \mathrm{~mA}$ for $30 \mathrm{~min}$ per gel and then $30 \mathrm{~mA}$ per gel until the bromophenol blue reached the bottom of the gels. Proteins were detected by a silver nitrate staining.

\section{Image analysis}

Analytical gels were scanned on an Image Scanner (GE healthcare) at 300 dpi with 12-bit gray scale levels in tagged image file format (TIFF), images were analyzed using the ImageMaster 2D Platinum (GE Healthcare). All gels in the analyses were scanned with identical parameters. The individual spots of each gel were detected by their boundaries and the spot volumes corresponding to the protein abundance were calculated automatically. Each spot intensity volume was processed by background subtraction and total spot volume normalization. The resulting spot volume percentage was used for comparison. Only those spots that have statistical significance in differential expression, as judged by software analysis of the silver-stained gels, were excised from gels for analysis by MS.

\section{In-gel digestion}

Each gel piece was rinsed three with deionized water, destained in a 1:1 solution of $30 \mathrm{mM}$ potassium ferricyanide and $100 \mathrm{mM}$ sodium thiosulfate and then equilibrated in $50 \mathrm{mM}$ ammonium bicarbonate to $\mathrm{pH}$ 8.0. After hydrating with acetonitrile and drying in a Speed Vac. The gel spots were rehydrated in a minimal volume of trypsin (Promega, USA) solution $\left(20 \mu \mathrm{g} / \mathrm{ml}\right.$ in $25 \mathrm{mM} \mathrm{NH}_{4} \mathrm{HCO}_{3}$ ) and incubated at $37^{\circ} \mathrm{C}$ overnight. The supernatants were transferred into a $200 \mu \mathrm{L}$ microcentrifuge tube and the gels were extracted once with extraction buffer (67\% acetonitrile containing $2.5 \%$ trifluoroacetic acid). The peptide extract and the supernatant of the gel spot were combined and then completely dried in a Speed Vac centrifuge.

\section{Protein identification and data analysis}

After digestion, tryptic peptides were lyophilized and resuspended in $2 \mu \mathrm{L}$ of a $30 \%$ acetonitrile/0.1\% TFA solution. $0.8 \mu \mathrm{L}$ of the samples were spotted onto the MALDI sample target plate, followed by $0.4 \mu \mathrm{L}$ of a saturated matrix solution of a-cyano-4-hydroxycinnamic acid prepared in 50\% acetonitrile/0.1\% TFA.

Peptide mass spectra were obtained on a MALDI-TOF/ TOF mass spectrometer (4800 Proteomics Analyzer, Applied Biosystems, Foster City, CA, USA) in the positive ion reflectron mode. After an external calibration with a 
mixture of Gradykinin (Mr, 904.458), angiotensin I (Mr, 1296.685), Glul-Fibrinopeptide (Mr, 1570.677), ACTH clip 1-17 (Mr, 2093.08), ACTH clip 18-39 (Mr, 2465.199), ACTH clip 7-38(Mr, 3657.929), spectra were obtained in the mass range between 900 and $3500 \mathrm{Da}$ with 500 laser shots. For each sample spot, a data dependent acquisition method was created to select the seven most intense peaks ( $\mathrm{S} / \mathrm{N}>50)$, excluding those from the matrix, due to trypsin autolysis or acrylamide peaks, for subsequent MS/MS data acquisition. MS/MS spectra were acquired with 1200 laser shots in the mass range from $10 \mathrm{Da}$ to the mass of parent ion using an interpretation method present on instrument software, where the seven most intense peaks were selected and MS/MS spectra were generated automatically.

Database search spectra were processed and analyzed by the Global Protein Server Workstation (Applied Biosystems, Foster City, CA, USA), which uses internal Mascot (Matrix Science Ltd, UK)software for searching the peptide mass fingerprints and MS/MS data. Searches were performed against the uniport database with the taxonomy of Homo sapiens. Mass searches were performed using mass tolerance settings of $100 \mathrm{ppm}$ for the precursor and 0.2 $\mathrm{Da}$ for the fragment masses. The following parameters were used in database searching: fixed modification, carbamidomethyl (cysteine), variable modification, oxidation (methionine), Up to one missed trypsin cleavage was allowed. To ensure a reliable identification, the results from both the MS and MS/MS spectra were used in the database search. Protein identification was accepted when the score reported by the Mascot search routine was higher than 62 and, whenever possible, confirmed with $\mathrm{MW} / \mathrm{pI}$ values.

\section{Protein categorization and network construction}

Identified proteins were classified based on the PANTHER (Protein ANalysis THrough Evolutionary Relationships) system (http://www.pantherdb.org), a unique resource that classifies genes and proteins by their functions. The PANTHER ontology, a highly controlled vocabulary (ontology terms) by molecular function, protein class and biological process was used to categorize proteins into families and subfamilies with shared functions.

The interaction network of the differentially expressed protein was generated with Pathway Studio version 5.0 software (Ariadne Genomis, Rockville, MD) and Resnet 5 database. Common upstream regulators or downstream targets of multiple proteins were identified by using this software that facilitated the process of selecting potential mechanisms and key factors from the large number of differentially regulated proteins.

\section{Western blot analysis}

Protein extracts from serum of normal and extremely severe HFMD were separated by SDS-PAGE (12-15\% acrylamide) and then electroblotted onto PVDF membranes. The membranes were incubated with Keratin type II cytoskeletal 6C(KRT6C),Serum amyloid P-component(APCS), Apolipoprotein A-1(APOA1) and Peroxiredoxin-2(PRDX2) antibodies at $4^{\circ} \mathrm{C}$ overnight, followed by incubation with

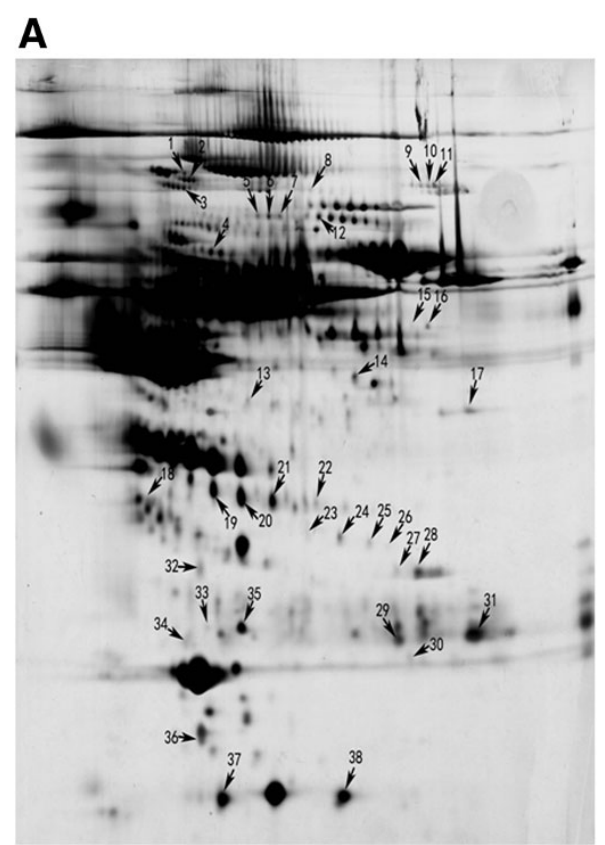

B

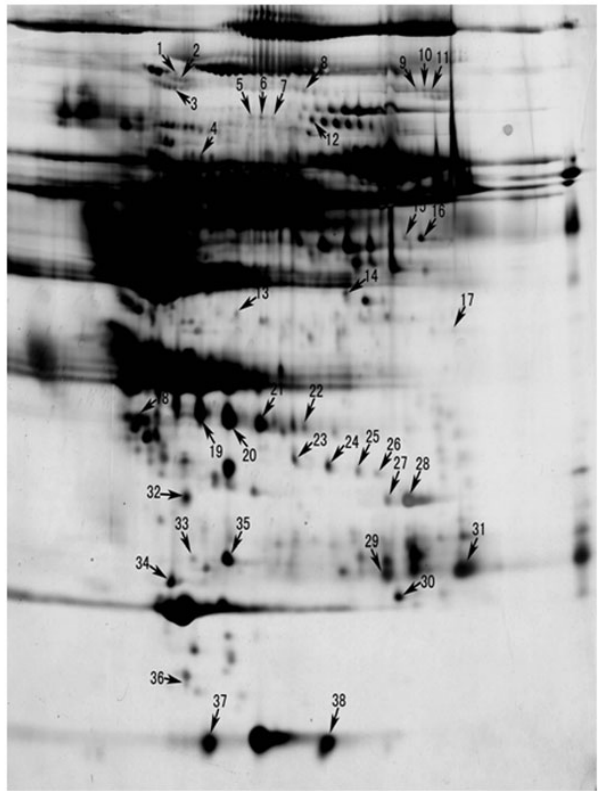

Figure 1 2-DE analysis of differentially expressed protein spots between healthy children (A) and extremely severe HFMD patients (B). The gels were visualized by silver staining. Differentially expressed proteins are marked using numbers, which correspond to the Table 1. 
corresponding secondary antibodies at room temperature for $2 \mathrm{~h}$. Specific protein bands were visualized with the SuperSignal chemiluminescence system (ECL, Pierce, USA) and imaged by autoradiography.

\section{Results}

Comparative proteomic analysis of extremely severe HFMD Same amount of serum proteins of normal persons and extremely severe HFMD patients were depleted of the

Table 1 Identification of differentially expressed proteins of extremely severe HFMD patients by MALDI-TOF/TOF

\begin{tabular}{|c|c|c|c|c|c|c|}
\hline Spot no* & Protein name & Accession NO. & Protein MW(kDa) & Protein pl & Protein score C.1.\% & Ratio $(\mathrm{S} / \mathrm{N})$ \\
\hline 1 & Ceruloplasmin & P00450 & 122.98 & 5.44 & 99.96 & -2.31 \\
\hline 2 & Ceruloplasmin & E9PFZ2 & 109.49 & 5.49 & 100 & -3.006 \\
\hline 3 & $35 \mathrm{kDa}$ inter-alpha-trypsin inhibitor heavy chain $\mathrm{H} 4$ & $\mathrm{~F} 5 \mathrm{H} 194$ & 98.55 & 6.21 & 100 & -3.574 \\
\hline 4 & Inter-alpha-trypsin inhibitor heavy chain $\mathrm{H} 2$ & P19823 & 106.85 & 6.4 & 100 & -1.889 \\
\hline 5 & Serum albumin & E7ESU5 & 72.46 & 5.82 & 100 & -3.598 \\
\hline 6 & Serum albumin (Fragment) & H0YA55 & 53.08 & 6.45 & 100 & -5.505 \\
\hline 7 & Serum albumin (Fragment) & HOYA55 & 53.08 & 6.45 & 100 & -3.019 \\
\hline 8 & C2ORF3 variant 2 & A4UHQ9 & 28.03 & 5.08 & 96.214 & 1.887 \\
\hline 9 & Plasminogen & P00747 & 93.25 & 7.04 & 99.995 & -2.122 \\
\hline 10 & Plasminogen & P00747 & 93.25 & 7.04 & 100 & -2.81 \\
\hline 11 & Plasminogen & P00747 & 93.25 & 7.04 & 99.987 & -2.981 \\
\hline 12 & Alpha-2-macroglobulin & P01023 & 164.61 & 6.03 & 100 & -1.5799 \\
\hline 13 & Pigment epithelium-derived factor & P36955 & 46.45 & 5.97 & 96.992 & 1.621 \\
\hline 14 & Hemopexin & P02790 & 52.38 & 6.55 & 100 & -1.566 \\
\hline 15 & Ig alpha-2 chain $C$ region & P01877 & 37.30 & 5.71 & 100 & 1000000 \\
\hline 16 & Cdna FU55673 highly similar to complement fator B & B4E1Z4 & 143.19 & 6.82 & 99.862 & 5.1141 \\
\hline 17 & Complement C3 & P01024 & 188.57 & 6.02 & 99.63 & -7.118 \\
\hline 18 & Clusterin alpha chain (Fragment) & HOYAS8 & 16.22 & 5.51 & 100 & 5.212 \\
\hline 19 & Haptoglobin beta chain & I3L0D3 & 31.67 & 8.48 & 100 & 1.612 \\
\hline 20 & Haptoglobin beta chain & 13L0D3 & 31.67 & 8.48 & 100 & 1.845 \\
\hline 21 & Haptoglobin beta chain & I3LOD3 & 31.67 & 8.48 & 100 & 1.8315 \\
\hline 22 & MTHFSD Uncharacterized & B7ZLC2 & 24.26 & 6.97 & 95.54 & 2.6638 \\
\hline 23 & Haptoglobin beta chain & I3L0D3 & 31.67 & 8.48 & 100 & 3.569 \\
\hline 24 & Isoform 1 of Ficolin-3 & O75636 & 33.40 & 6.20 & 100 & 1.8743 \\
\hline 25 & Isoform 2 of Ficolin-3 & O75636 & 32.11 & 6.36 & 100 & 1.9465 \\
\hline 26 & Apolipoprotein L1 & E9PF24 & 42.19 & 5.58 & 96.777 & 1000000 \\
\hline 27 & complement component $4 \mathrm{~B}$ preproprotein & B4E344 & 194.17 & 6.89 & 99.987 & 2.1058 \\
\hline 28 & DADB-112B14.11 Complement component 4B & BOUZ85 & 194.17 & 6.89 & 100 & 2.404 \\
\hline 29 & IGK@protein & Q6P5S8 & 26.04 & 5.94 & 99.398 & 2.004 \\
\hline 30 & Peroxiredoxin-2 & P32119 & 22.05 & 5.66 & 100 & 9.686 \\
\hline 31 & Ig kappa chain V-III region WOL & P01623 & 11.85 & 9.07 & 100 & 2.489 \\
\hline 32 & Keratin, type II cytoskeletal 1 & P04264 & 66.17 & 8.15 & 99.112 & 2.4587 \\
\hline 33 & Keratin, type II cytoskeletal 6C & P48668 & 60.27 & 8.09 & 100 & 2.5654 \\
\hline 34 & Apolipoprotein A-1 & P02647 & 30.76 & 5.56 & 100 & 4.3662 \\
\hline 35 & Serum amyloid P-component & P02743 & 25.49 & 6.10 & 100 & 3.863 \\
\hline 36 & Retinol-binding protein 4 & P02753 & 23.34 & 5.76 & 100 & -2.876 \\
\hline 37 & Haptoglobin beta chain & HOY300 & 22.53 & 5.96 & 97.871 & 1.527 \\
\hline 38 & HPR 47 kDa protein & P00738 & 47.38 & 6.28 & 100 & 1.7345 \\
\hline
\end{tabular}

"1000000"-only appeared in the extremely severe HFMD patients, but not appeared in the healthy children.

*Spot numbers correspond to the numbers marked in Figure 1.

Note: some proteins showed in the 2-DE as multiple spots, probably due to their isoforms and/or modifications. 
high-abundance proteins like albumin and IgG to reduce their disturbance to the detection of low-abundance proteins. The samples were then subjected to 2-DE followed by silver staining (Figure 1A for controls and Figure 1B for patients). The gels were scanned and compared with ImageMaster 2D Platinum software to identify the protein spot variations (Table 1). We identified 38 differentially expressed proteins from the 2-D gels and identified them by MALDI TOF/TOF MS. Among these, 24 proteins were up-regulated and 14 proteins were down-regulated in the extremely severe HFMD samples compared with the level in control samples. Two proteins appeared exclusively in the extremely severe HFMD patients, not in the healthy children.

\section{Validation of differentially expressed proteins in extremely severe HFMD}

To verify the differential expression of proteins in extremely severe HFMD, we used western blot analysis to examine the expression of three proteins, including KRT6C, APCS, APOA1 and PRDX2. The Western blotting results showed the same pattern of expression as obtained from 2-DE analysis. That is, they are significantly increased in extremely severe HFMD (Figure 2).

\section{Functional categories and biological interaction networking of identified proteins}

In order to understand the biological relevance of the changes in protein expression in extremely severe HFMD, PANTHER [17] software was used to categorize the identified proteins according to their molecular functions, biological process and protein class (Figure 3). The result showed an enrichment of the binding proteins (31\%) and enzyme regulators (23\%) (Figure 3A). The patients had altered metabolic process $(22 \%)$ and enhanced response to stimulus (13\%), indicating that the body was in a stress condition (Figure 3B). The immune system was also stimulated to counteract the lesion caused by the virus (16\%) (Figure 3B). The enrichment is not protein-class specific, indicating a complex response in the case of HFMD (Figure 3C).

Bioinformatic analysis using Pathway Studio [18] software enabled the characterization of biological association networks related to these differentially expressed proteins (Figure 4). The proteins that could be networked were linked by various relationships such as expression regulations, modifications and protein interactions. The network showed complex interactions of extracellular and intracellular proteins, as well as nuclear proteins and a mitochondria protein, indicating a complex signaling network involving transcription regulation and mitochondria signaling pathways.

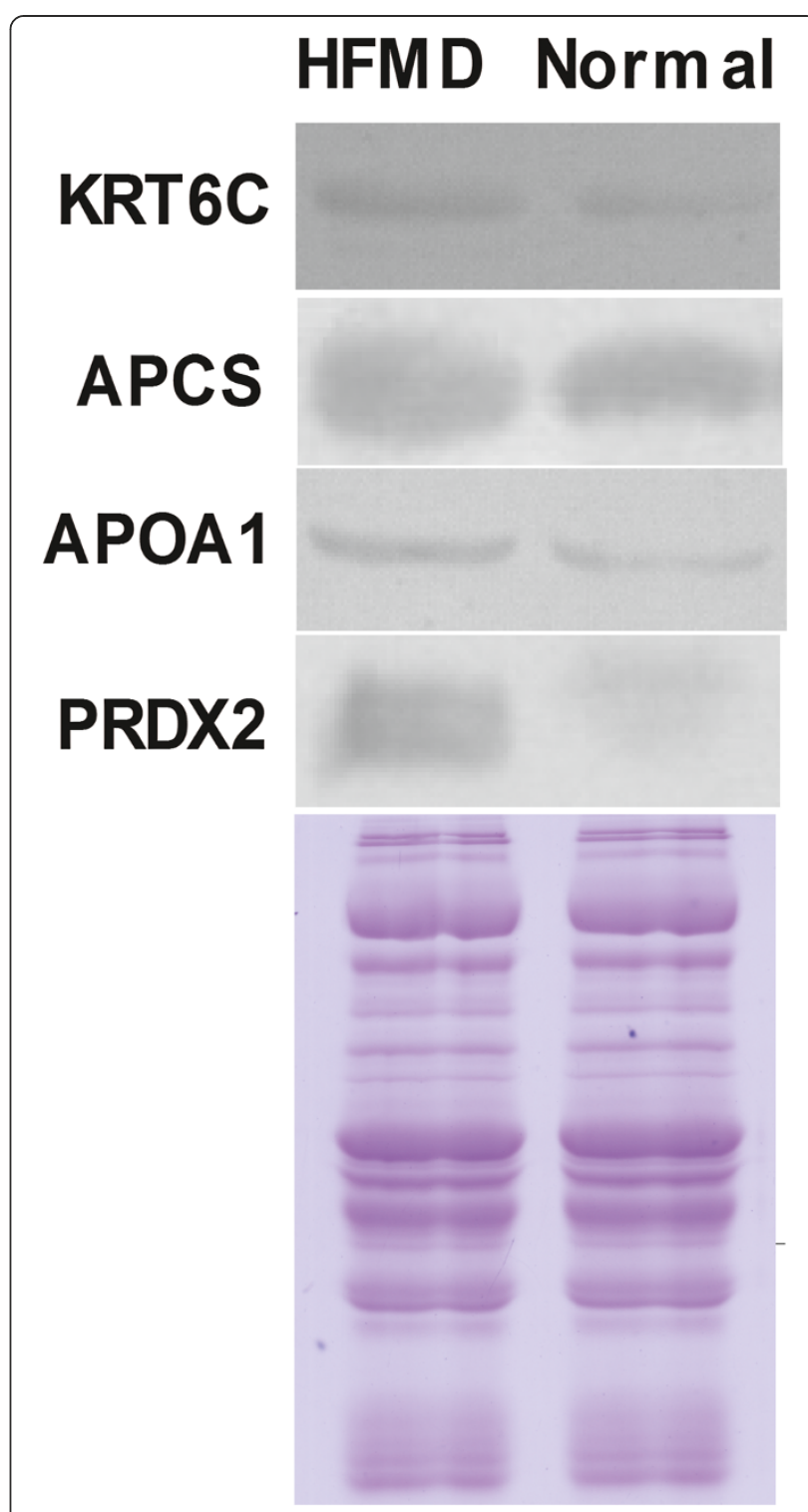

Figure 2 Western blot validation of four proteins (KRT6C, APCS, APOA1 and PRDX2) in extremely severe HFMD serum samples, and the Coomassie -stained blot (below) is the loading control.

\section{Discussion}

There are no effective antiviral drugs and vaccines available against HFMD, therefore the timely and accurate diagnosis and monitoring is crucial for the treatment. In the present study, we took advantage of proteomics to identify potential markers which reflect the status of HFMD. The goals were to (i) define a set of differentially expressed proteins that may be used as potential biomarkers to facilitate the severe HFMD diagnosis and monitoring of therapy effectiveness and (ii) gain a deeper understanding of the early pathological processes in severe HFMD. 

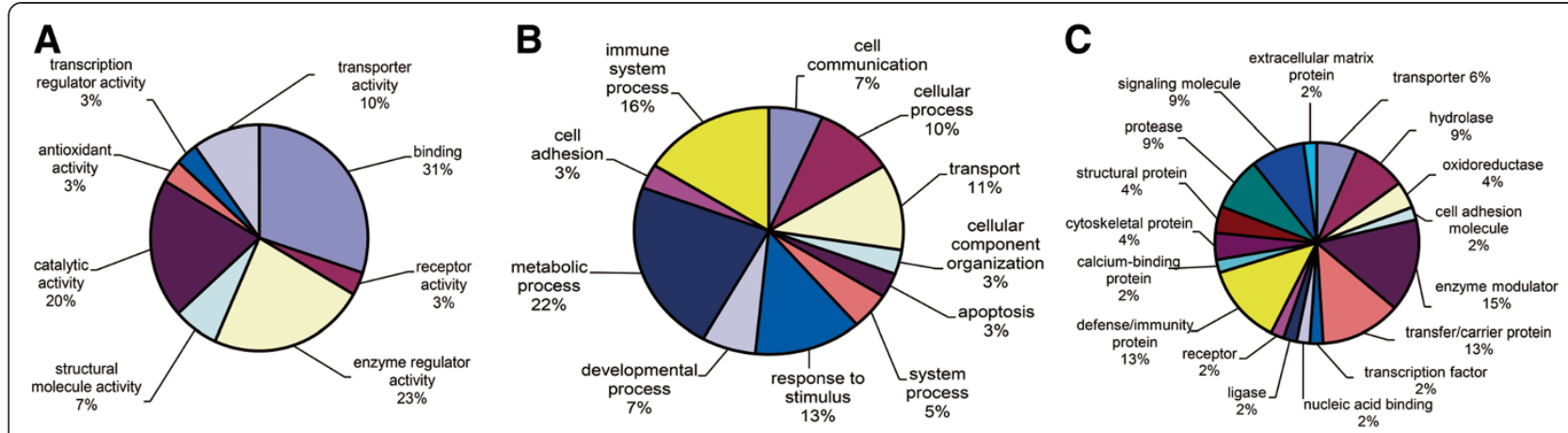

Figure 3 Functional classification of identified differentially expressed proteins from extremely severe HFMD serum samples according to their (A) molecular functions, (B) biological processes and (C) protein class.

We identified 38 differentially expressed spots which were detected in the serum of extremely severe HFMD patients compared with the healthy controls (Table 1). The known functions of these proteins are summarized in Figure 2 . These proteins have previously been identified using proteomics approaches in mild and severe HFMD children [19]. However, a change in their expression in relation to extremely severe HFMD had never been previously reported. Extremely severe HFMD represent the most acute and serious situation of this disease and usually life-threatening. Biomarkers for this stage can serve as a warning signal for an urgent treatment. A variety of cellular functions was covered from the identified proteins, including enzyme modulator, infection defense/immunity,

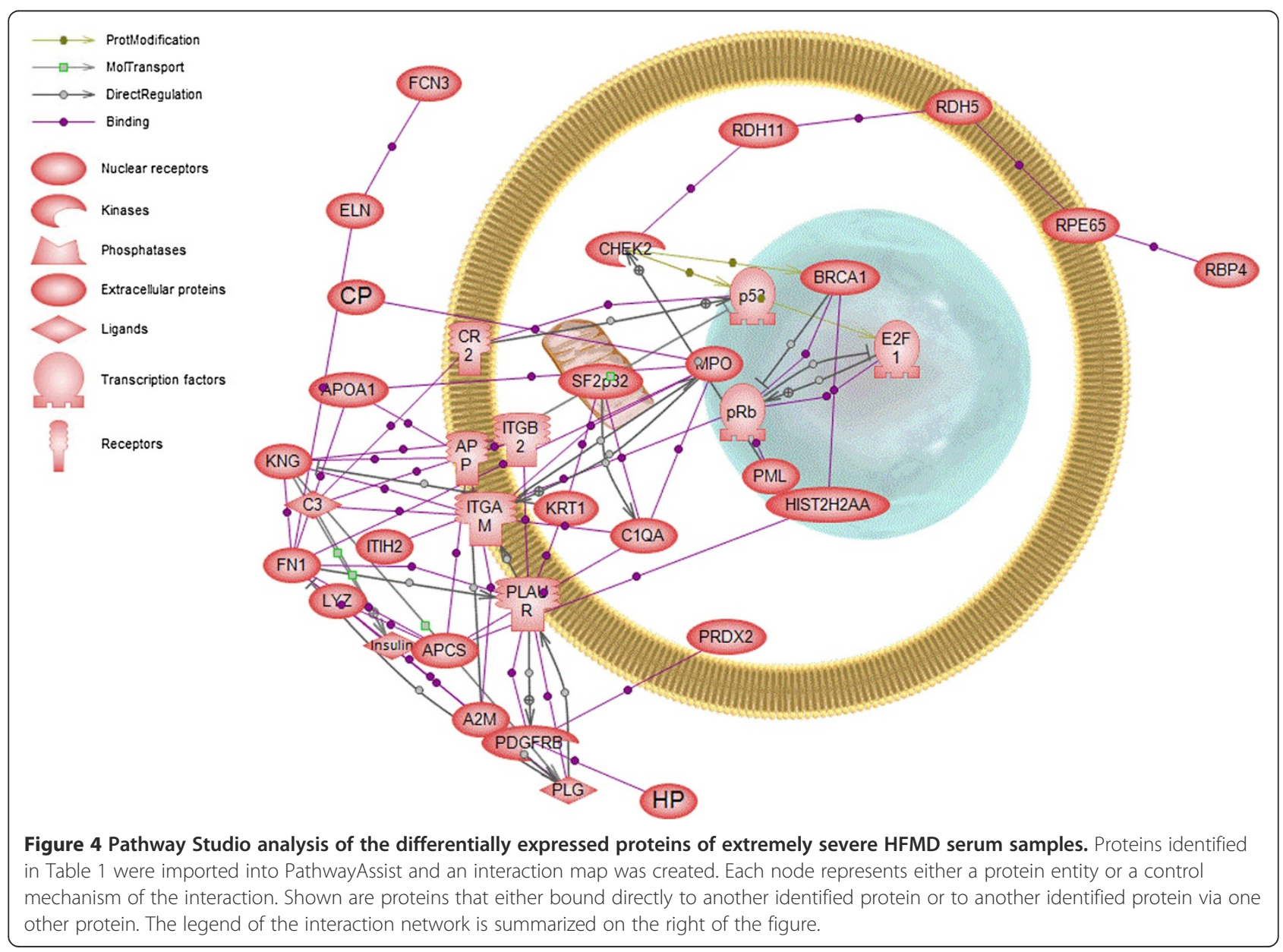


signaling molecule, cytoskeleton maintenance, metabolism etc., reflecting the human body facing acute lesions.

Our study showed an apparent down regulation of Complement C3(C3), inter-alpha (globulin) inhibitor H2 (ITIH2), serum albumin (ALB), plasminogen (PLG) and retinol binding protein 4 (RBP4) [20-22]. The function of these proteins typically involve in virus invasion protection and elimination; histamine release and muscle smooth; colloidal osmotic pressure of blood regulation and retinol delivery. Thus, down regulation of the proteins indicated that the viral infection suppressed these reactions from HFMD patients, facilitating the disease progression. Inhibition of the viral protection enhances the virulence of the virus, leading to extremely severe symptoms and even fatal lesions. This suggested that antiviral therapies may help to control the disease progression in the extremely severe phase.

Previous studies have noted that many diseases, including the neurological diseases known as transmissible spongiform encephalopathies (TSEs), are due to inflammatory injury [23]. EV71 infection can induce complement activation and an inflammatory response of the central nervous system. Inappropriate or excessive activation of the complement system can result in severe inflammation or tissue injury $[24,25]$. It was known that complement C3 plays a key role in the activation of the complement system [26]. From our study we found that the C3 was the most down regulated protein of the extremely severe HFMD. These information together with our results imply the activation of complement system due to EV71 infection and inflammatory is associated with complement activation. Whilst antiviral therapy is one possible approach, it is perhaps more important to inhibit the inflammatory response. Complement inhibition should greatly reduce the inflammatory reaction or tissue injury resulting from excess complement activation.

Peroxiredoxin-2 (PRDX2) was found extremely significant increased in extremely severe HFMD patient. It plays an important role in eliminating peroxides generated during metabolism. It participates the signaling cascades of growth factors and tumor necrosis factoralpha by regulating the intracellular concentrations of $\mathrm{H}_{2} \mathrm{O}_{2}$. It is one of the most important antioxidant enzymes in humans $[27,28]$. Previous studies showed that antioxidant enzymes activity, increased in severe HFMD patients and decreased significantly after vincristineadriamycin- dexamethasone therapy [29]. Therefore, we speculate that upregulation of PRDX2 may play significant roles in pathogenesis of severe HFMD and could be used as the potential drug targets.

\section{Conclusions}

We reported, for the first time, the analysis in a proteome level to identify proteins that change in expression in extremely severe HFMD. These proteins have the potential to be used, probably in combination, as potential molecular markers to monitor the progression of HFMD treatment. The results also suggested the crucial pathways in the development of the disease in extremely severe phase, providing important hints for the functional studies and therapy design of HFMD. Further validation with a much larger sample size is necessary to determine the biomarker set for clinical applications.

\section{Competing interests}

The authors declare that they have no competing interests.

\section{Authors' contributions}

$L D, H L J$ and $C W L$ created the concept and design of this study. $C H H, G Q Y$, $J H L$ and JPT participated in sample diagnosis and collection. YFX and LJM performed the experiments. HLJ and LZ were responsible for the statistical analysis. $L D, H L J$ and $L Z$ drafted, revised and edited the manuscript. All authors read and approved the final manuscript.

\section{Acknowledgement}

This work was supported by National Clinical Key Specialty Project Foundation, Guangdong Natural Science Foundation (9151008901000033), Applied Basic Research Program of Technology and Information Bureau Guangzhou City (2013J4100022), Dean Foundation (GW201238) of School of Public Health and Tropical Medicine, Southern Medical University.

\section{Author details}

'Guangzhou Women and Children's medical center, Guangzhou 510120, Guangdong, China. ${ }^{2}$ Key Laboratory of Functional Protein Research of Guangdong Higher Education Institutes, Institute of Life and Health Engineering, College of Life Science and Technology, Jinan University, Guangzhou 510632, Guangdong, China. ${ }^{3}$ School of Public Health and Tropical Medicine, Southern Medical University, Guangzhou 510515, Guangdong, China. ${ }^{4}$ Guangdong Institute of Microbiology/Guangdong Provincial Key Laboratory of Microbial Culture Collection and Application, Guangzhou 510070, Guangdong, China.

Received: 10 March 2013 Accepted: 16 August 2013

Published: 20 August 2013

\section{References}

1. Schmidt NJ, Lennette $\mathrm{EH}, \mathrm{Ho} H \mathrm{H}$ : An apparently new enterovirus isolated from patients with disease of the central nervous system. J Infect Dis 1974, 129(3):304-309.

2. Lum LC, Wong KT, Lam SK, Chua KB, Goh AY, Lim WL, Ong BB, Paul G, AbuBakar S, Lambert M: Fatal enterovirus 71 encephalomyelitis. J Pediatr 1998, 133(6):795-798.

3. Lum LC, Wong KT, Lam SK, Chua KB, Goh AY: Neurogenic pulmonary oedema and enterovirus 71 encephalomyelitis. Lancet 1998, 352(9137):1391.

4. Ho M, Chen ER, Hsu KH, Twu SJ, Chen KT, Tsai SF, Wang JR, Shih SR: An epidemic of enterovirus 71 infection in Taiwan. Taiwan Enterovirus Epidemic Working Group. N Engl J Med 1999, 341(13):929-935.

5. Chan KP, Goh KT, Chong CY, Teo ES, Lau G, Ling AE: Epidemic hand, foot and mouth disease caused by human enterovirus 71, Singapore. Emerg Infect Dis 2003, 9(1):78-85.

6. Zhang Y, Tan XJ, Wang HY, Yan DM, Zhu SL, Wang DY, Ji F, Wang XJ, Gao $Y J$, Chen $L$, et al: An outbreak of hand, foot, and mouth disease associated with subgenotype C4 of human enterovirus 71 in Shandong. China. J Clin Virol 2009, 44(4):262-267.

7. Zhang Y, Zhu Z, Yang W, Ren J, Tan X, Wang Y, Mao N, Xu S, Zhu S, Cui A: An emerging recombinant human enterovirus 71 responsible for the 2008 outbreak of hand foot and mouth disease in Fuyang city of China. Virol J 2008, 7:94.

8. Jia L, Zhao CS, Zhang L, Li S, Zhang DT, Liu BW, Wang QY, Li XY: [Comparisons of epidemiological and clinical characteristics in children with hand-foot-mouth disease caused by Enterovirus 71 and Coxackievirus A16]. Zhongguo Dang Dai Er Ke Za Zhi 2011, 13(8):635-637. 
9. Wang X, Zhu C, Bao W, Zhao K, Niu J, Yu XF, Zhang W: Characterization of full-length enterovirus 71 strains from severe and mild disease patients in northeastern China. PLoS One 2012, 7(3):e32405.

10. Wang SM, Liu CC: Enterovirus 71: epidemiology, pathogenesis and management. Expert Rev Anti Infect Ther 2009, 7(6):735-742.

11. Chen SC, Chang HL, Yan TR, Cheng YT, Chen KT: An eight-year study of epidemiologic features of enterovirus 71 infection in Taiwan. Am J Trop Med Hyg 2007, 77(1):188-191.

12. Briese T, Palacios G, Kokoris M, Jabado O, Liu Z, Renwick N, Kapoor V, Casas I, Pozo F, Limberger R, et al: Diagnostic system for rapid and sensitive differential detection of pathogens. Emerg Infect Dis 2005, 11(2):310-313.

13. Foo DG, Ang RX, Alonso S, Chow VT, Quak SH, Poh CL: Identification of immunodominant VP1 linear epitope of enterovirus 71 (EV71) using synthetic peptides for detecting human anti-EV71 IgG antibodies in Western blots. Clin Microbiol Infect 2008, 14(3):286-288.

14. Wang SY, Lin TL, Chen HY, Lin TS: Early and rapid detection of enterovirus 71 infection by an IgM-capture ELISA. J Virol Methods 2004, 119(1):37-43.

15. Xu F, Yan Q, Wang H, Niu J, Li L, Zhu F, He S, Zhang S, Weng Z, Cheng T: Performance of detecting $\lg \mathrm{M}$ antibodies against enterovirus 71 for early diagnosis. PLoS One 2010, 5(6):e11388.

16. Sherman M, Peltekian KM, Lee C: Screening for hepatocellular carcinoma in chronic carriers of hepatitis B virus: incidence and prevalence of hepatocellular carcinoma in a North American urban population. Hepatology 1995, 22(2):432-438.

17. Jia H, Liu C, Ge F, Xiao C, Lu C, Wang T, He Q: Identification of ubiquitinated proteins from human multiple myeloma U266 cells by proteomics. Biomed Environ Sci 2011, 24(4):422-430.

18. Xiao CL, Zhang ZP, Xiong S, Lu CH, Wei HP, Zeng HL, Liu Z, Zhang XE, Ge F: Comparative proteomic analysis to discover potential therapeutic targets in human multiple myeloma. Proteomics Clin App/ 2009, 3(11):1348-1360.

19. Deng L, Jia HL, Liu CW, Hu KH, Yin GQ, Ye JW, He CH, Chen JH, Xie YP, Dang R: Analysis of differentially expressed proteins involved in hand, foot and mouth disease and normal sera. Clin Microbiol Infect 2012, 18(6):E188-196.

20. Enghild JJ, Salvesen G, Thogersen IB, Valnickova Z, Pizzo SV, Hefta SA: Presence of the protein-glycosaminoglycan-protein covalent cross-link in the inter-alpha-inhibitor-related proteinase inhibitor heavy chain 2/ bikunin. J Biol Chem 1993, 268(12):8711-8716.

21. Sunthornthepvarakul T, Angkeow P, Weiss RE, Hayashi Y, Refetoff S: An identical missense mutation in the albumin gene results in familial dysalbuminemic hyperthyroxinemia in 8 unrelated families. Biochem Biophys Res Commun 1994, 202(2):781-787.

22. Ichinose A, Espling ES, Takamatsu J, Saito H, Shinmyozu K, Maruyama I, Petersen TE, Davie EW: Two types of abnormal genes for plasminogen in families with a predisposition for thrombosis. Proc Natl Acad Sci U S A 1991, 88(1):115-119.

23. Sjoberg AP, Trouw LA, Blom AM: Complement activation and inhibition: a delicate balance. Trends Immuno/ 2009, 30(2):83-90.

24. Ricklin D, Hajishengallis G, Yang K, Lambris JD: Complement: a key system for immune surveillance and homeostasis. Nat Immunol 2010, 11(9):785-797.

25. Zhang C, Xu Y, Jia L, Yang Y, Wang Y, Sun Y, Huang L, Qiao F, Tomlinson S, Liu $X$ : A new therapeutic strategy for lung tissue injury induced by influenza with CR2 targeting complement inhibitor. Virol J 2010, 7:30.

26. Shih SR, Stollar V, Lin JY, Chang SC, Chen GW, Li ML: Identification of genes involved in the host response to enterovirus 71 infection. J Neurovirol 2004, 10(5):293-304.

27. Crack PJ, Taylor JM, Flentjar NJ, De Haan J, Hertzog P, lannello RC, Kola I: Increased infarct size and exacerbated apoptosis in the glutathione peroxidase-1 (Gpx-1) knockout mouse brain in response to ischemia/ reperfusion injury. J Neurochem 2001, 78(6):1389-1399.
28. Hussain SP, Amstad P, He P, Robles A, Lupold S, Kaneko I, Ichimiya M, Sengupta S, Mechanic L, Okamura S, et al: p53-induced up-regulation of MnSOD and GPx but not catalase increases oxidative stress and apoptosis. Cancer Res 2004, 64(7):2350-2356.

29. Kuku I, Aydogdu I, Bayraktar N, Kaya E, Akyol O, Erkurt MA: Oxidant/ antioxidant parameters and their relationship with medical treatment in multiple myeloma. Cell Biochem Funct 2005, 23(1):47-50.

doi:10.1186/1471-2334-13-383

Cite this article as: Deng et al.: Proteomic analysis of extremely severe hand, foot and mouth disease infected by enterovirus 71. BMC Infectious Diseases 2013 13:383.

\section{Submit your next manuscript to BioMed Central and take full advantage of:}

- Convenient online submission

- Thorough peer review

- No space constraints or color figure charges

- Immediate publication on acceptance

- Inclusion in PubMed, CAS, Scopus and Google Scholar

- Research which is freely available for redistribution

Submit your manuscript at www.biomedcentral.com/submit
C) BioMed Central 